\title{
A comparison of minimally invasive transforaminal lumbar interbody fusion and decompression alone for degenerative lumbar spondylolisthesis
}

\author{
Andrew K. Chan, MD, ${ }^{1}$ Erica F. Bisson, MD, MPH, ${ }^{2}$ Mohamad Bydon, MD, ${ }^{3}$ \\ Steven D. Glassman, MD, ${ }^{4}$ Kevin T. Foley, MD, ${ }^{5}$ Eric A. Potts, MD, ${ }^{6}$ Christopher I. Shaffrey, MD, ${ }^{7}$ \\ Mark E. Shaffrey, MD, ${ }^{8}$ Domagoj Coric, MD, ${ }^{9}$ John J. Knightly, MD, ${ }^{10}$ Paul Park, MD, ${ }^{11}$ \\ Michael Y. Wang, MD,12 Kai-Ming Fu, MD, PhD, ${ }^{13}$ Jonathan R. Slotkin, MD, ${ }^{14}$ Anthony L. Asher, MD, ${ }^{9}$ \\ Michael S. Virk, MD, PhD, ${ }^{13}$ Panagiotis Kerezoudis, MD, MS, ${ }^{3}$ Mohammed Ali Alvi, MBBS, ${ }^{3}$ \\ Jian Guan, MD, ${ }^{2}$ Regis W. Haid, MD, ${ }^{15}$ and Praveen V. Mummaneni, MD ${ }^{1}$
}

'Department of Neurological Surgery, University of California, San Francisco, California; ${ }^{2}$ Department of Neurological Surgery, University of Utah, Salt Lake City, Utah; ${ }^{3}$ Department of Neurological Surgery, Mayo Clinic, Rochester, Minnesota; ${ }^{4}$ Norton Leatherman Spine Center, Louisville, Kentucky; ${ }^{5}$ Department of Neurological Surgery, University of Tennessee; SemmesMurphey Neurologic and Spine Institute, Memphis, Tennessee; 'Department of Neurological Surgery, Indiana University, Goodman Campbell Brain and Spine, Indianapolis, Indiana; ' ${ }^{7}$ Departments of Neurological Surgery and Orthopedic Surgery, Duke University, Durham, North Carolina; ${ }^{8}$ Department of Neurological Surgery, University of Virginia Health System, Charlottesville, Virginia; ${ }^{N}$ Neuroscience Institute, Carolinas Healthcare System and Carolina Neurosurgery \& Spine Associates, Charlotte, North Carolina; ${ }^{10} \mathrm{Atlantic}$ Neurosurgical Specialists, Morristown, New Jersey; ${ }^{11}$ Department of Neurological Surgery, University of Michigan, Ann Arbor, Michigan; ${ }^{12}$ Department of Neurological Surgery, University of Miami, Florida; ${ }^{13}$ Department of Neurological Surgery, Weill Cornell Medical Center, New York, New York; ${ }^{14}$ Geisinger Health, Danville, Pennsylvania; and ${ }^{15}$ Atlanta Brain and Spine Care, Atlanta, Georgia

OBJECTIVE The optimal minimally invasive surgery (MIS) approach for grade 1 lumbar spondylolisthesis is not clearly elucidated. In this study, the authors compared the 24-month patient-reported outcomes (PROs) after MIS transforaminal lumbar interbody fusion (TLIF) and MIS decompression for degenerative lumbar spondylolisthesis.

METHODS A total of 608 patients from 12 high-enrolling sites participating in the Quality Outcomes Database (QOD) lumbar spondylolisthesis module underwent single-level surgery for degenerative grade 1 lumbar spondylolisthesis, of whom 143 underwent MIS (72 MIS TLIF [50.3\%] and 71 MIS decompression [49.7\%]). Surgeries were classified as MIS if there was utilization of percutaneous screw fixation and placement of a Wiltse plane MIS intervertebral body graft (MIS TLIF) or if there was a tubular decompression (MIS decompression). Parameters obtained at baseline through at least 24 months of follow-up were collected. PROs included the Oswestry Disability Index (ODI), numeric rating scale (NRS) for back pain, NRS for leg pain, EuroQol-5D (EQ-5D) questionnaire, and North American Spine Society (NASS) satisfaction questionnaire. Multivariate models were constructed to adjust for patient characteristics, surgical variables, and baseline PRO values.

RESULTS The mean age of the MIS cohort was $67.1 \pm 11.3$ years (MIS TLIF 62.1 years vs MIS decompression 72.3 years) and consisted of 79 (55.2\%) women (MIS TLIF 55.6\% vs MIS decompression 54.9\%). The proportion in each cohort reaching the 24-month follow-up did not differ significantly between the cohorts (MIS TLIF $83.3 \%$ and MIS decompression $84.5 \%, p=0.85$ ). MIS TLIF was associated with greater blood loss (mean 108.8 vs $33.0 \mathrm{ml}, p<0.001$ ), longer operative time (mean 228.2 vs 101.8 minutes, $p<0.001$ ), and longer length of hospitalization (mean 2.9 vs 0.7 days, $p$ $<0.001)$. MIS TLIF was associated with a significantly lower reoperation rate $(14.1 \%$ vs $1.4 \%, p=0.004)$. Both cohorts demonstrated significant improvements in ODI, NRS back pain, NRS leg pain, and EQ-5D at 24 months $(p<0.001$, all comparisons relative to baseline). In multivariate analyses, MIS TLIF-as opposed to MIS decompression alone-was

ABBREVIATIONS MIS = minimally invasive surgery; NASS = North American Spine Society; NRS = numeric rating scale; ODI = Oswestry Disability Index; PRO = patientreported outcome; $\mathrm{QOD}=$ Quality Outcomes Database; $\mathrm{RCT}=$ randomized controlled trial; TLIF = transforaminal lumbar interbody fusion.

SUBMITTED December 22, 2018. ACCEPTED February 22, 2019.

INCLUDE WHEN CITING DOI: 10.3171/2019.2.FOCUS18722. 
associated with superior ODI change $(\beta=-7.59,95 \% \mathrm{Cl}-14.96$ to $-0.23 ; p=0.04)$, NRS back pain change $(\beta=-1.54$, $95 \% \mathrm{Cl}-2.78$ to $-0.30 ; p=0.02$ ), and NASS satisfaction (OR 0.32, 95\% Cl 0.12-0.82; $p=0.02$ ).

CONCLUSIONS For symptomatic, single-level degenerative spondylolisthesis, MIS TLIF was associated with a lower reoperation rate and superior outcomes for disability, back pain, and patient satisfaction compared with posterior MIS decompression alone. This finding may aid surgical decision-making when considering MIS for degenerative lumbar spondylolisthesis.

https://thejns.org/doi/abs/10.3171/2019.2.FOCUS18722

KEYWORDS spondylolisthesis; minimally invasive; Quality Outcomes Database; patient-reported outcomes; transforaminal lumbar interbody fusion

$\mathrm{D}$ EGENERATIVE lumbar spondylolisthesis is an important cause of low-back pain, affecting up to $12 \%$ of the United States population. ${ }^{19}$ Surgical treatment is effective ${ }^{39}$ and is considered when conservative treatment fails. Surgical management may include decompression with or without the addition of fusion. Recent randomized controlled trials (RCTs) ${ }^{13,16}$ and a prospective registry study ${ }^{7}$ arrived at somewhat differing conclusions about the utility of the addition of fusion, with the studies that focused exclusively on the population with grade 1 lumbar spondylolisthesis favoring the addition of fusion. Importantly, none of the aforementioned studies focused their investigation on a minimally invasive surgery (MIS) population, so it remains unclear whether fusion is beneficial for patients undergoing MIS alone.

MIS techniques are advocated as a means to decrease pain, narcotic use, blood loss, hospital length of stay, surgical site infection, and cost and to expedite recovery and return to work. 1,10,25,28,31,32,34-38 Advantages of MIS techniques include avoiding disruption of paraspinal musculature, facet joints, and ligamentous structures, which may lead to increased pain and destabilization of the spine. Disadvantages include a more technically demanding procedure with a learning curve and the lack of "open" visualization of bony and neural anatomy. Given the increasing prevalence of MIS, ${ }^{12}$ a contemporaneous understanding of the effect of MIS fusion-compared with MIS decompression alone-for spondylolisthesis is of interest.

To this end, we analyzed a prospective, multicenter, and multidisciplinary registry to compare outcomes following MIS transforaminal lumbar interbody fusion (TLIF; Fig. 1) and MIS decompression for symptomatic, single-level, grade 1 degenerative lumbar spondylolisthesis.

\section{Methods}

The Quality Outcomes Database (QOD) is a prospective, multicenter, multidisciplinary registry that includes demographic, clinical, and patient-reported outcome (PRO) data to measure the safety and quality of spinal surgery. Twelve of the high-enrolling QOD sites participate in the lumbar spondylolisthesis module/study group., ${ }^{4,828} \mathrm{We}$ queried the lumbar spondylolisthesis module from July 2014 through June 2016 for patients undergoing singlesegment, posterior-approach surgery for grade 1 lumbar spondylolisthesis. Preoperative plain radiographs (standing or dynamic) were obtained and were evaluated by sur- geons at the participating sites to confirm the diagnosis of grade 1 spondylolisthesis as defined by the Meyerding classification. ${ }^{27}$ In this study, we identified patients who underwent surgery via MIS techniques as defined previously. ${ }^{28}$ In short, surgeries were classified as MIS if there was utilization of percutaneous screw fixation and placement of a Wiltse plane MIS intervertebral body graft (MIS TLIF) or if there was a tubular decompression (MIS decompression). Procedures that involved only a component of MIS (e.g., "partially" MIS, involving an "open" component) were not classified as MIS. In addition to QOD exclusion criteria, ${ }^{26}$ we excluded patients who had grade 2 or higher spondylolisthesis. For all eligible patients, all variables were audited for data element accuracy.

\section{Demographic, Clinical, and Surgical Variables}

The QOD registry collects data on demographic variables (age, sex, BMI, ethnicity, insurance, education level, employment), patient comorbidities (smoking, diabetes, anxiety, osteoporosis, depression, American Society of Anesthesiologists classification), clinical characteristics (dominant presenting symptom, ambulation status, symptom duration, presence of motor deficit), baseline and follow-up PRO scores (Oswestry Disability Index [ODI], EuroQol-5D [EQ-5D], numeric rating scale [NRS] for leg pain, NRS for back pain, North American Spine Society [NASS] satisfaction questionnaire), and surgical variables (use of MIS TLIF vs MIS decompression, estimated blood loss, operative time, length of hospitalization, discharge disposition, readmission rate, reoperation rate). Readmissions and reoperations were recorded if deemed related to surgery.

Ethnicity (Hispanic or Latino vs not Hispanic or Latino), insurance status (private insurance vs Medicare, Medicaid, or Veterans Affairs/government), education level (4-year degree after high school education or greater vs less than a 4-year degree after high school education), employment status (employed or on leave vs unemployed), ambulation status (independently ambulatory vs nonindependently ambulatory [e.g., with an assistive device]), and discharge disposition (discharge to home or home healthcare vs discharge not to home or home healthcare) were 2-level variables. The dominant presenting symptom was a 3-level variable (back pain predominant, leg pain predominant, or back and leg pain equally predominant). Symptom duration was dichotomized as greater or less than 3 months. 


\section{Primary and Secondary Outcomes}

We assessed outcomes at baseline and 24 months using validated questionnaires. The primary outcome of interest was ODI score. Secondary outcomes of interest included NRS back pain, NRS leg pain, EQ-5D questionnaire, and NASS satisfaction questionnaire. The NASS satisfaction questionnaire assesses patient satisfaction following surgery via a survey with 4 answer choices scored 1 through 4, respectively: "surgery met my expectations," "I did not improve as much as I had hoped but I would undergo the same operation for the same results," "surgery helped but I would not undergo the same operation for the same results," and "I am the same or worse as compared to before surgery."

\section{Statistical Analysis}

Descriptive statistics were reported as means and standard deviations and frequencies and percentages where appropriate. For multivariate analyses, multivariate linear regression models were fitted for changes in ODI, EQ-5D, NRS back pain, and NRS leg pain scores at 24 months (i.e., 24-month value - baseline value). For each model, covariates included factors reaching $\mathrm{p}<0.20$ on univariate comparisons and respective baseline PROs. An ordinal logistic regression model was fit for the NASS satisfaction questionnaire score after controlling for covariates reaching $\mathrm{p}<0.20$ on univariate comparisons. This analysis was conducted using R 2.15.2 (R: A language and environment for statistical computing, $\mathrm{R}$ Foundation for Statistical Computing). Missing values in the data were imputed using the "missForest" $\mathrm{R}$ package28; $\mathrm{p}$ values were 2-tailed and an alpha of 0.05 was considered statistically significant.

\section{Results}

From July 1, 2014, through June 30, 2016, there were 608 patients in the QOD lumbar spondylolisthesis module at the 12 participating sites who underwent single-segment surgery for grade 1 degenerative lumbar spondylolisthesis. Of these, 143 (23.5\%) cases utilized posterior-based MIS techniques: 72 (50.3\%) MIS TLIF and 71 (49.7\%) MIS decompressions. Descriptive variables are presented in Table 1. Patients undergoing MIS TLIF were younger (62.1 vs 72.3 years, $\mathrm{p}<0.001)$, were less likely to have diabetes mellitus ( $9.7 \%$ vs $22.5 \%, p=0.04$ ), and had different symptoms on presentation, with the MIS TLIF cohort demonstrating a higher proportion of back pain-predominant symptoms $(45.8 \%$ vs $28.2 \%, \mathrm{p}<0.001)$ and a lower rate of baseline motor deficit (5.6\% vs 36.6\%, p < 0.001). Patients in the MIS TLIF cohort had a higher use of private insurance $(65.3 \%$ vs $26.8 \%, \mathrm{p}<0.001)$, and a greater proportion were employed or employed and on leave ( $54.2 \%$ vs $23.9 \%$, $\mathrm{p}<0.001)$. The cohort with MIS TLIF had higher NRS back pain scores at baseline (mean $6.9 \pm 2.6$ vs $5.6 \pm 3.3$, $\mathrm{p}=0.01)$.

Table 2 lists the surgical variables, including perioperative and long-term outcomes. Compared with the MIS decompression cohort, the MIS TLIF group had significantly greater blood loss (108.8 vs $33.0 \mathrm{ml}, \mathrm{p}<0.001)$, longer operative times (228.2 vs 101.8 minutes, $\mathrm{p}<0.001)$,

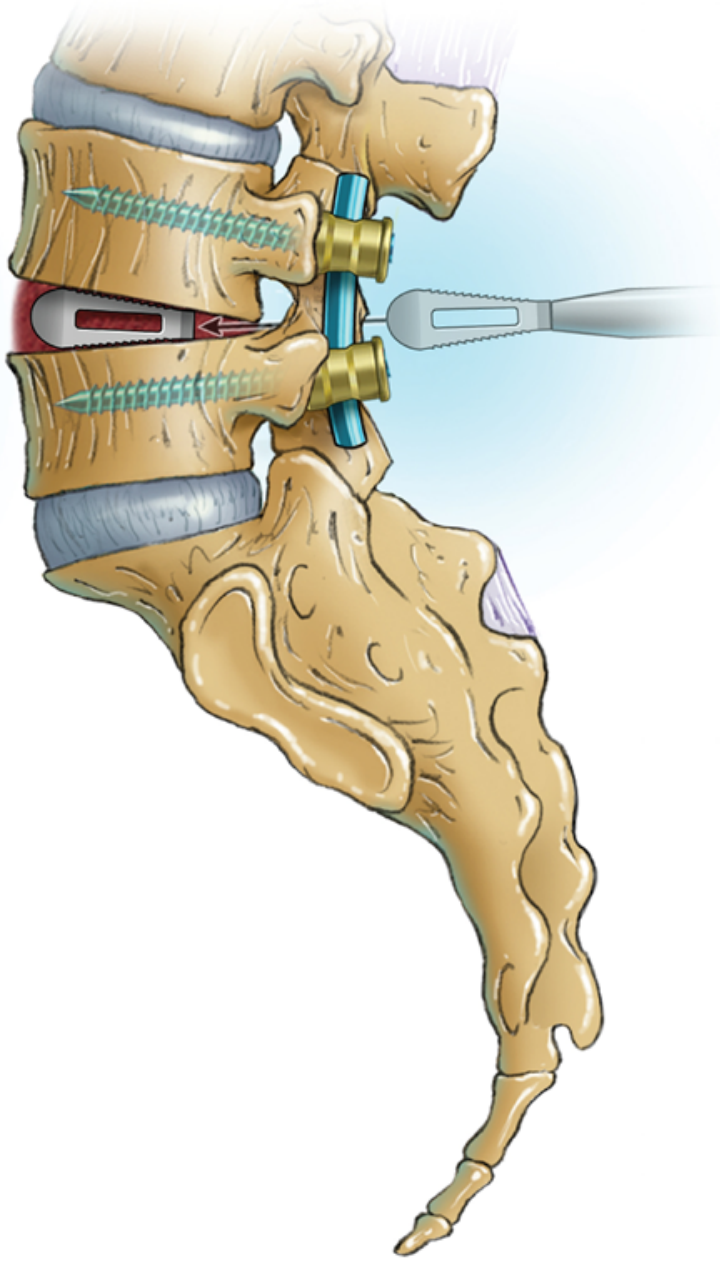

FIG. 1. Illustration depicting an L4-5 TLIF. Reprinted from Chan AK, et al: J Neurosurg Spine 30:234-241, 2019. Artist: Kenneth Probst. Copyright Department of Neurological Surgery, University of California, San Francisco. Published with permission.

and longer lengths of hospitalization (2.9 vs 0.7 days, $\mathrm{p}$ $<0.001)$. At the 24-month follow-up, MIS TLIF was associated with significantly fewer reoperations $(1[1.4 \%]$ vs 10 [14.1\%], $\mathrm{p}=0.004)$. Table 3 provides the reasons for reoperation. Discharge disposition and readmission rates did not differ significantly $(\mathrm{p}>0.05)$.

Table 4 demonstrates the changes in PRO scores and NASS satisfaction at 24 months. The MIS TLIF cohort had a greater mean ODI change $(-30.3 \pm 20.7$ vs $-15.1 \pm$ $20.7, \mathrm{p}<0.001)$, greater NRS back pain change $(-4.7 \pm 3.2$ vs $-1.5 \pm 4.4, p<0.001)$, and superior satisfaction $(71.2 \%$ vs $47.3 \%$ NASS score 1 [most satisfied], $\mathrm{p}=0.02$ ). There were no significant differences between the MIS TLIF and decompression cohorts with regard to 24-month change in NRS leg pain or EQ-5D score.

For the MIS TLIF cohort, the mean ODI improved significantly at the 24-month follow-up $(14.3 \pm 17.2)$ compared with baseline $(46.2 \pm 16.3)(\mathrm{p}<0.001)$. NRS back pain improved significantly at the 24-month follow-up (2.3 $\pm 2.9)$ compared with baseline $(6.9 \pm 2.6)(\mathrm{p}<0.001)$. NRS 
TABLE 1. Characteristics of patients undergoing surgery for grade 1 lumbar spondylolisthesis

\begin{tabular}{|c|c|c|c|}
\hline & MIS TLIF $(n=72)$ & MIS Decompression $(n=71)$ & $\mathrm{p}$ Value \\
\hline Mean age, yrs & $62.1 \pm 10.6$ & $72.3 \pm 9.7$ & $<0.001$ \\
\hline Female, $\mathrm{n}(\%)$ & $40(55.6)$ & $39(54.9)$ & 0.94 \\
\hline Mean BMI & $29.5 \pm 5.1$ & $28.2 \pm 4.7$ & 0.11 \\
\hline Smoker, n (\%) & $9(12.5)$ & $8(11.3)$ & 0.82 \\
\hline \multicolumn{4}{|l|}{ Comorbidities, n (\%) } \\
\hline Diabetes mellitus & $7(9.7)$ & $16(22.5)$ & 0.04 \\
\hline Coronary artery disease & $9(12.5)$ & $14(19.7)$ & 0.24 \\
\hline Anxiety & $11(15.3)$ & $11(15.5)$ & 0.97 \\
\hline Depression & $16(22.2)$ & $10(14.1)$ & 0.21 \\
\hline Osteoporosis & $3(4.2)$ & $7(9.9)$ & 0.31 \\
\hline Dominant presenting symptom, $n(\%)$ & & & $<0.001$ \\
\hline Back pain dominant & $33(45.8)$ & $20(28.2)$ & \\
\hline Leg pain dominant & $10(13.9)$ & $36(50.7)$ & \\
\hline Back pain = leg pain & $29(40.3)$ & $15(21.1)$ & \\
\hline Motor deficit present at presentation, $\mathrm{n}(\%)$ & $4(5.6)$ & $26(36.6)$ & $<0.001$ \\
\hline Independently ambulatory, n (\%) & $64(88.9)$ & $61(85.9)$ & 0.59 \\
\hline Symptom duration, $\mathrm{n}(\%)$ & & & NA \\
\hline$<3$ mos & $0(0)$ & $4(5.6)$ & \\
\hline$>3$ mos & $69(95.8)$ & $64(90.1)$ & \\
\hline ASA class, $n(\%)$ & & & 0.15 \\
\hline | or I| & $42(58.3)$ & $52(73.2)$ & \\
\hline III or IV & $26(36.1)$ & $19(26.8)$ & \\
\hline Hispanic or Latino ethnicity, n (\%) & $5(6.9)$ & $1(1.4)$ & 0.22 \\
\hline$\geq 4$ yrs of college education, $n(\%)$ & $29(40.3)$ & $36(50.7)$ & 0.21 \\
\hline Employed or employed \& on leave, n (\%) & $39(54.2)$ & $17(23.9)$ & $<0.001$ \\
\hline Private insurance, $\mathrm{n}(\%)$ & $47(65.3)$ & $19(26.8)$ & $<0.001$ \\
\hline Mean baseline ODI score & $46.2 \pm 16.3$ & $41.0 \pm 18.9$ & 0.08 \\
\hline Mean baseline NRS back pain score & $6.9 \pm 2.6$ & $5.6 \pm 3.3$ & 0.01 \\
\hline Mean baseline NRS leg pain score & $6.3 \pm 2.8$ & $6.2 \pm 3.0$ & 0.92 \\
\hline Mean baseline EQ-5D score & $0.58 \pm 0.20$ & $0.58 \pm 0.22$ & 0.98 \\
\hline >2-yr follow-up rate, n (\%) & $60(83.3)$ & $60(84.5)$ & 0.85 \\
\hline
\end{tabular}

ASA = American Society of Anesthesiologists; NA = not applicable.

Values do not add up to $100 \%$ where there are missing data. Mean values are presented with SD. Boldface type indicates statistical significance.

leg pain improved significantly at the 24-month follow-up $(1.6 \pm 2.7)$ compared with baseline $(6.3 \pm 2.8)(\mathrm{p}<0.001)$. EQ-5D improved significantly at the 24-month follow-up $(0.84 \pm 0.17)$ compared with baseline $(0.58 \pm 0.20)(\mathrm{p}<$ $0.001)$.

Similarly, for the MIS decompression cohort, there was significant improvement in the mean ODI $(23.3 \pm 19.1$ from $41.0 \pm 18.9)$, NRS back pain (3.6 \pm 2.9 from 5.6 \pm 3.3$)$, NRS leg pain $(2.4 \pm 3.1$ from $6.2 \pm 3.0)$, and EQ-5D $(0.80 \pm 0.15$ from $0.58 \pm 0.22$ ) scores at the 24-month follow-up compared with baseline ( $\mathrm{p}<0.001$, all comparisons). Figure 2 demonstrates PRO scores at baseline and 24 months after surgery. At 24 months, the mean ODI $(p=0.008)$ and NRS back pain $(p=0.02)$ were superior in the MIS TLIF cohort compared with the MIS decompression cohort. There were no significant differences for NRS leg pain and EQ-5D at 24 months ( $\mathrm{p}=0.11$ and $\mathrm{p}=0.18$, respectively).

\section{Multivariate Analysis}

We conducted a multivariate analysis to adjust for potential confounders. Significant predictors of 24-month change scores (ODI, NRS back pain, NRS leg pain, and EQ-5D) and 24-month NASS satisfaction are reported in Table 5. In adjusted analyses, MIS TLIF-as opposed to MIS decompression alone-was associated with superior ODI change $(\beta=-7.59,95 \% \mathrm{CI}-14.96$ to $-0.23 ; \mathrm{p}=$ $0.04)$, NRS back pain change ( $\beta=-1.54,95 \% \mathrm{CI}-2.78$ to $-0.30 ; \mathrm{p}=0.02$ ), and NASS satisfaction (OR $0.32,95 \% \mathrm{CI}$ $0.12-0.82 ; \mathrm{p}=0.02$ ).

Additional factors significantly associated with changes in multiple 24-month PRO scores included baseline PROs, preoperative employment at presentation, a diagnosis of diabetes mellitus, and the dominant presenting symptom. Employment was associated with superior ODI change ( $\beta$ 
TABLE 2. Hospital data for patients undergoing MIS for grade 1 lumbar spondylolisthesis

\begin{tabular}{|c|c|c|c|}
\hline & $\begin{array}{l}\text { MIS TLIF } \\
(n=72)\end{array}$ & $\begin{array}{l}\text { MIS Decompression } \\
\qquad(\mathrm{n}=71)\end{array}$ & $p$ Value \\
\hline Mean EBL, ml & $108.8 \pm 85.6$ & $33.0 \pm 63.7$ & $<0.001$ \\
\hline Mean op time, mins & $228.2 \pm 111.5$ & $101.8 \pm 48.5$ & $<0.001$ \\
\hline $\begin{array}{l}\text { Mean length of hospi- } \\
\text { talization, days }\end{array}$ & $2.9 \pm 1.8$ & $0.7 \pm 1.2$ & $<0.001$ \\
\hline Discharge disposition & & & 0.76 \\
\hline $\begin{array}{l}\text { Home or home } \\
\text { healthcare, } \\
\mathrm{n}(\%)\end{array}$ & 67 (93.1) & $66(93.0)$ & \\
\hline $\begin{array}{l}\text { Other than home } \\
\text { or home health- } \\
\text { care, } \mathrm{n}(\%)\end{array}$ & $5(6.9)$ & $5(7.0)$ & \\
\hline $\begin{array}{l}\text { 3-mo readmission, } \\
\text { n (\%) }\end{array}$ & $2(2.8)$ & $3(4.2)$ & $>0.99$ \\
\hline $\begin{array}{l}\text { Reop during 24-mo } \\
\text { follow-up, } n(\%)\end{array}$ & $1(1.4)$ & $10(14.1)$ & 0.004 \\
\hline Death, $n(\%)$ & $0(0)$ & $0(0)$ & NA \\
\hline
\end{tabular}

EBL = estimated blood loss.

Mean values are presented with SD. Boldface type indicates statistical significance.

$=-10.48,95 \% \mathrm{CI}-17.52$ to $-3.44 ; \mathrm{p}=0.004)$, NRS back pain change score $(\beta=-1.52,95 \% \mathrm{CI}-2.70$ to -0.33 ; $\mathrm{p}$ $=0.01)$, EQ-5D change $(\beta=0.07,95 \%$ CI $0.01-0.14 ; \mathrm{p}=$ 0.02 ), and NASS satisfaction (OR $0.21,95 \%$ CI $0.08-0.54$; $\mathrm{p}=0.002$ ). Diabetes mellitus was associated with inferior ODI change score $(\beta=9.96,95 \%$ CI $1.57-18.35 ; p=0.02)$ and EQ-5D change score $(\beta=-0.09,95 \% \mathrm{CI}-0.17$ to $-0.01 ; \mathrm{p}=0.02$ ). A dominant presenting symptom of back pain was associated with inferior ODI change $(\beta=8.50$, 95\% CI 1.33-15.67; $\mathrm{p}=0.02$ ) and NRS leg pain change $(\beta=1.29,95 \%$ CI $0.09-2.48 ; p=0.04)$. Each respective baseline PRO was also associated with 24-month change scores (Table 5).

\section{Discussion}

In an analysis of 143 patients undergoing MIS for grade 1 degenerative lumbar spondylolisthesis, we found that MIS TLIF was associated with superior outcomes for disability, back pain, and patient satisfaction compared with posterior MIS decompression alone. Additionally, we found that MIS TLIF was associated with a lower rate of reoperation. Additional factors were associated with superior improvements in PROs. Patient employment was associated with superior improvement in disability, back pain, quality of life, and satisfaction. Patients with diabetes mellitus had inferior outcomes for disability and quality of life. Patients who had a dominant presentation of back pain-as opposed to leg pain or back equaling leg pain-had less improvement in disability and leg pain. More severe baseline disease (e.g., higher ODI, NRS back and leg pain, and lower EQ-5D) was associated with greater 24-month improvements in PROs.
TABLE 3. Reasons for reoperation in the MIS TLIF and MIS decompression cohorts

\begin{tabular}{ccc}
\hline & $\begin{array}{c}\text { No. of } \\
\text { Reops (\%) }\end{array}$ & Comment \\
\hline MIS TLIF $(\mathrm{n}=72)$ & $1(1.4)$ & $\begin{array}{c}\text { ASD requiring extension of } \\
\text { fusion w/in } 12 \text { mos }\end{array}$ \\
\hline $\begin{array}{c}\text { MIS decompression } \\
(\mathrm{n}=71)\end{array}$ & $10(14.1)$ & \\
\hline $\begin{array}{c}\text { Revision decompres- } \\
\text { sion }\end{array}$ & $6(8.5)$ & $\begin{array}{c}4(5.6 \%) \text { w/in } 12 \text { mos; } 2 \\
(2.8 \%) \text { btwn } 12 \& 24 \text { mos }\end{array}$ \\
\hline Fusion & $4(5.6)$ & $2(2.8 \%)$ w/in 12 mos; 2 \\
& & $(2.8 \%)$ btwn $24 \& 36$ mos \\
\hline
\end{tabular}

ASD = adjacent-segment disease .

The benefit of the addition of fusion in the MIS-only cohort is consistent with a prior RCT by Ghogawala et al. ${ }^{16}$ (an open-only cohort) and a prior report by our group utilizing the prospective QOD registry ${ }^{7}$ (combined open and MIS cohort). Herein, we demonstrate the association between the addition of fusion-via MIS TLIF-and superior ODI, back pain, and satisfaction 2 years after surgery.

This protective effect of MIS TLIF on 2-year ODI outcomes extends the findings reported by our study group comparing outcomes for fusion and decompression alone 1 year following non-MIS-specific degenerative lumbar spondylolisthesis surgery. In the study, we found that the addition of fusion was associated with superior ODI. ${ }^{7}$ This is in contrast to the Swedish Spinal Stenosis Study (SSSS) by Försth et al., in which no significant benefit for ODI was seen with the addition of fusion to decompression alone. ${ }^{13}$ Of note, the SSSS was likely underpowered to detect differences in ODI and suffered from a heterogeneous population, including both 1 and 2 levels of stenosis and patients with and without mobile spondylolisthesis, as the study lacked preoperative dynamic radiographs. Presently, we include only patients with symptomatic, single-level spondylolisthesis.

The association between the addition of fusion and sat-

TABLE 4. PROs for patients undergoing MIS for grade 1 lumbar spondylolisthesis

\begin{tabular}{lccc}
\hline & $\begin{array}{c}\text { MIS TLIF } \\
(n=72)\end{array}$ & $\begin{array}{c}\text { MIS } \\
\text { Decompression } \\
(n=71)\end{array}$ & $\begin{array}{c}p \\
\text { Value }\end{array}$ \\
\hline Mean $\Delta$ ODI score & $-30.3 \pm 20.7$ & $-15.1 \pm 20.7$ & $<0.001$ \\
\hline Mean $\Delta$ NRS back pain score & $-4.7 \pm 3.2$ & $-1.5 \pm 4.4$ & $<0.001$ \\
\hline Mean $\Delta$ NRS leg pain score & $-4.5 \pm 3.9$ & $-3.8 \pm 3.7$ & 0.32 \\
\hline Mean $\Delta$ EQ-5D & $+0.26 \pm 0.22$ & $+0.18 \pm 0.25$ & 0.09 \\
\hline NASS satisfaction, $n(\%)$ & & & 0.02 \\
\hline 1 & $42(71.2)$ & $26(47.3)$ & \\
\hline 2 & $13(22.0)$ & $14(25.5)$ & \\
\hline 3 & $1(1.4)$ & $6(10.9)$ & \\
\hline 4 & $3(4.2)$ & $9(16.4)$ & \\
\hline
\end{tabular}

Mean values are presented with SD. Boldface type indicates statistical significance. 

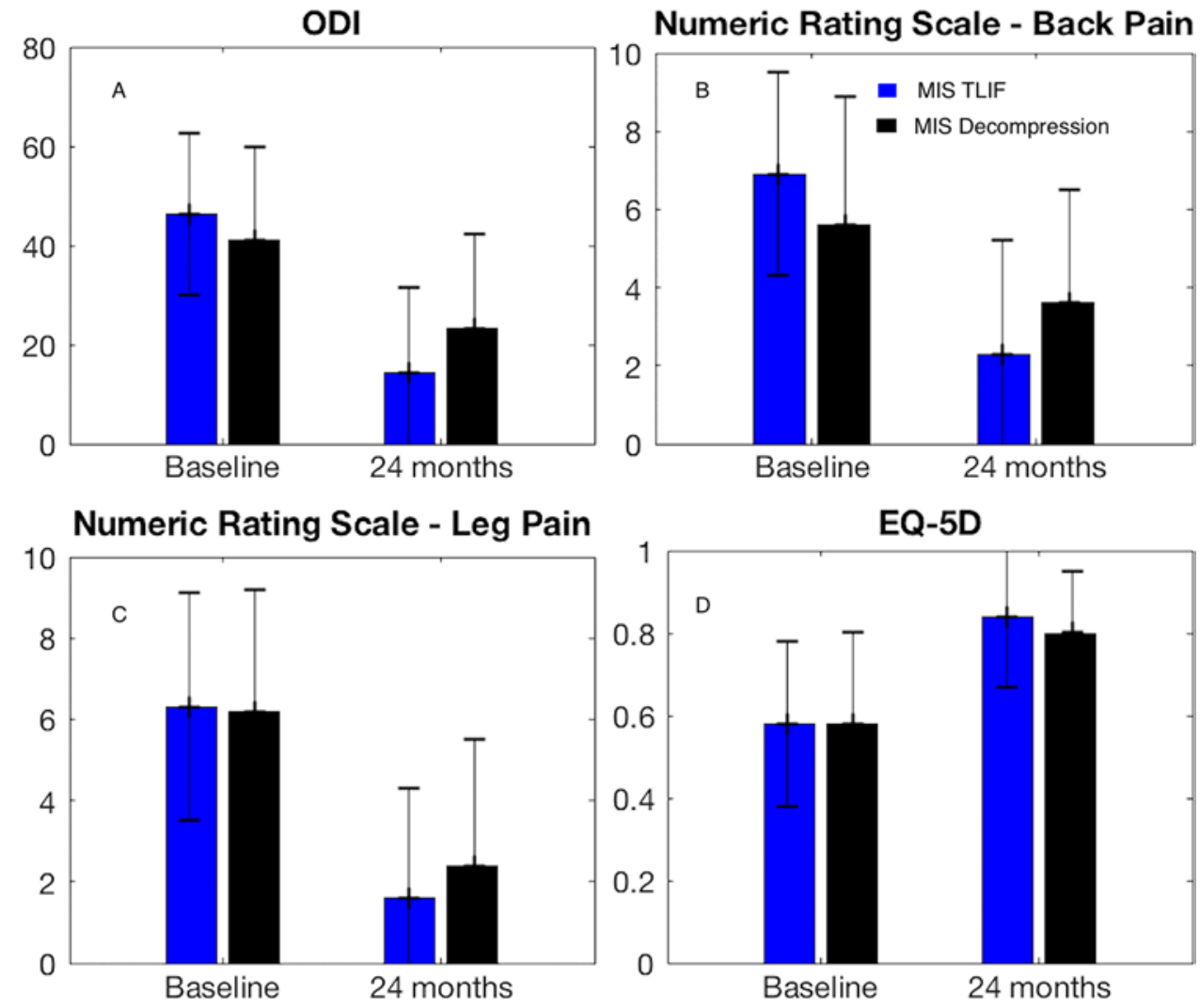

FIG. 2. PROs following MIS TLIF and MIS decompression surgery for grade 1 lumbar spondylolisthesis. Average ODI scores (A), NRS back pain (B), NRS leg pain (C), and EQ-5D (D) at baseline and 24 months after surgery. The error bars represent 1 standard deviation. There were statistically significant improvements at the 24-month follow-up relative to baseline for ODI, NRS back pain, NRS leg pain, and EQ-5D ( $p<0.001$, all comparisons). At baseline, the mean NRS back pain score was greater in the MIS TLIF cohort $(p=0.01)$. Otherwise, there were no statistically significant differences for ODI, NRS leg pain, and EQ-5D $(p=0.08, p=$ 0.92 , and $p=0.98$, respectively). At 24 months, the mean ODI $(p=0.008)$ and NRS back pain $(p=0.02)$ scores were superior in the MIS TLIF compared with the MIS decompression cohort. There were no significant differences for NRS leg pain and EQ-5D at 24 months ( $p=0.11$ and $p=0.18$, respectively).

isfaction has been reported previously for traditional open spondylolisthesis surgery. In a recent meta-analysis by Liang et al.,22 which included 4 RCTs and 13 observational studies comparing the clinical effectiveness of decompression with and without fusion for degenerative lumbar spondylolisthesis, pooled satisfaction rates were significantly higher following spinal fusion. However, a majority of patients receiving decompression alone surgery remained satisfied as well, suggesting that satisfaction is multifactorial and may be attributable to other patient (e.g., age, sex, comorbidities, clinical presentation), surgical (type of decompressive technique), and radiographic (degenerative status of a disc and slip progression) factors. ${ }^{5,6,8,15,18}$, $20,22,23,29,30$

Of note, in the meta-analysis by Liang et al.-reporting on open surgical techniques-significant relationships between the addition of fusion and ODI and of fusion and back pain were not detected. ${ }^{22}$ However, a significant relationship was detected between the addition of fusion and leg pain. On the other hand, the present MIS-focused study reveals significant relationships with MIS TLIF and back pain, but not between MIS TLIF and leg pain. These somewhat conflicting findings may reveal unique baseline characteristics of patients undergoing open versus MIS spondylolisthesis surgery or differential disease progression following each respective surgery.

It is suggested that a laminectomy alone may destabilize the spine after degenerative spondylolisthesis surgery, resulting in increasing back pain and reoperation in up to one-third of patients. ${ }^{16}$ In preventing this destabilizationassociated back pain, fusion surgery may permit greater improvements in back pain, which is consistent with the data reported here. Interestingly, one may expect the addition of a fusion to make less of an impact in the MIS population given that an MIS decompression should result in less destabilization due to avoidance of disruption of the paraspinal musculature and posterior tension band. However, the association between MIS decompression alone and higher reoperation rate and inferior disability and back pain may suggest that MIS is not as "destabilization proof" as suggested. Our results suggest that tubular decompression does not effectively minimize the limitations associated with open decompression in the grade 1 spondylolisthesis population.

When comparing MIS TLIF and MIS decompression, avoidance of additional surgical intervention is a key con- 
TABLE 5. Significant predictors of 24-month outcomes following MIS for grade 1 lumbar spondylolisthesis

\begin{tabular}{|c|c|c|}
\hline & $\begin{array}{c}\text { Adjusted } \beta \text { Coefficient } \\
(95 \% \mathrm{Cl})^{*}\end{array}$ & $\begin{array}{c}p \\
\text { Value }\end{array}$ \\
\hline \multicolumn{3}{|l|}{$\Delta$ ODI† } \\
\hline Addition of fusion to procedure & $-7.59(-14.96$ to -0.23$)$ & 0.04 \\
\hline Diabetes mellitus & $9.96(1.57$ to 18.35$)$ & 0.02 \\
\hline \multicolumn{3}{|l|}{ Dominant presenting symptom } \\
\hline Back = leg pain & Ref & \\
\hline Back pain & 8.50 (1.33 to 15.67$)$ & 0.02 \\
\hline Employed or employed \& on leave & $-10.48(-17.52$ to -3.44$)$ & 0.004 \\
\hline Baseline ODI & $-0.63(-0.81$ to -0.45$)$ & $<0.001$ \\
\hline \multicolumn{3}{|l|}{ DNRS back pain } \\
\hline Addition of fusion to procedure & $-1.54(-2.78$ to -0.30$)$ & 0.02 \\
\hline Employed or employed \& on leave & $-1.52(-2.70$ to -0.33$)$ & 0.01 \\
\hline Baseline NRS back pain & $-0.93(-1.12$ to -0.74$)$ & $<0.001$ \\
\hline \multicolumn{3}{|l|}{$\Delta N R S$ leg pain§ } \\
\hline Dominant presenting symptom & & 0.04 \\
\hline Back = leg pain & Ref & \\
\hline Back pain & 1.29 (0.09 to 2.48$)$ & \\
\hline Baseline NRS back pain & $-0.32(-0.51$ to -0.12$)$ & 0.002 \\
\hline Baseline NRS leg pain & $-0.69(-0.90$ to -0.47$)$ & $<0.001$ \\
\hline \multicolumn{3}{|l|}{$\Delta \mathrm{EQ}-5 \mathrm{D}$} \\
\hline Diabetes mellitus & $-0.09(-0.17$ to -0.01$)$ & 0.02 \\
\hline Employed or employed \& on leave & $0.07(0.01$ to 0.14$)$ & 0.02 \\
\hline \multirow[t]{2}{*}{ Baseline EQ-5D } & $-0.90(-1.06$ to -0.74$)$ & $<0.001$ \\
\hline & Adjusted OR (95\% Cl) & \\
\hline \multicolumn{3}{|l|}{ NASS satisfaction** } \\
\hline Addition of fusion to procedure & $0.32(0.12$ to 0.82$)$ & 0.02 \\
\hline Employed or employed \& on leave & $0.21(0.08$ to 0.54$)$ & 0.002 \\
\hline
\end{tabular}

Multivariate models adjusted for factors with $p<0.20$ on univariate comparisons were age, BMI, diabetes mellitus, dominant presenting symptom, motor deficit on presentation, ASA class, employment status, use of private insurance, baseline ODI, baseline NRS back pain, and whether or not the procedure was a fusion (TLIF). Additionally, we included baseline NRS leg pain and $E Q-5 D$ for those respective models. Boldface type indicates statistical significance.

* $\beta$ coefficients are reported such that a negative value for ODI, NRS back pain, and NRS leg pain and a positive value for EQ-5D represent superior outcomes at 24 months. ORs are reported such that an OR $<1.0$ for NASS satisfaction represents greater satisfaction at 24 months.

† For ODI, the addition of fusion, active employment, and worse baseline ODI was associated with superior ODI change scores. Diabetes mellitus and a dominant presentation of back pain were associated with inferior ODI change scores.

‡ For NRS back pain, the addition of fusion, active employment, and worse baseline back pain was associated with superior NRS back pain change scores.

$\S$ For NRS leg pain, worse baseline back pain and leg pain were associated with superior NRS leg pain change scores. A dominant presentation of back pain was associated with inferior NRS leg pain change scores.

Tf For EQ-5D, active employment and worse baseline EQ-5D portended superior EQ-5D change scores. Diabetes mellitus was associated with inferior EQ-5D change scores.

${ }^{* *}$ For NASS satisfaction, the addition of fusion and active employment was associated with superior satisfaction. cern. We found a significantly lower rate of reoperation in long-term follow-up for MIS TLIF than for MIS decompression alone $(1.4 \%$ vs $14.1 \%)$ - consistent with the SLIP (Spinal Laminectomy versus Instrumented Pedicle Screw) trial ${ }^{16}$ - suggesting that MIS TLIF is more durable than MIS decompression for degenerative lumbar spondylolisthesis when utilizing minimally invasive techniques. Future study should compare MIS decompression and fusion surgery with MIS decompression surgery for lumbar spondylolisthesis in a randomized controlled fashion. There is clearly a knowledge gap given the open-only surgery within the SLIP trial ${ }^{16}$ and dearth of MIS-only investigations of spondylolisthesis surgery. ${ }^{22,28}$

\section{Patient-Related Factors: Diabetes Mellitus and Dominant Presenting Symptom}

Diabetes has previously been associated with inferior outcomes following spondylolisthesis surgery. In a subgroup analysis of 594 patients who underwent surgery for degenerative spondylolisthesis in SPORT (Spine Patient Outcomes Research Trial), Freedman et al. reported that diabetic patients demonstrated inferior improvement compared with their nondiabetic counterparts with regard to ODI and SF-36 pain and physical function scores. ${ }^{14}$ This may be a result of a clinical picture that may be confounded by comorbid peripheral nerve lesions, vascular insufficiency leading to vascular claudication (which may be mistaken for leg pain of spinal etiology), ${ }^{21}$ or primary diabetic polyneuropathy. These factors may also decrease the capacity of nerve roots to recover after surgical manipulation. ${ }^{11,14}$ Indeed, surgeons and patients with diabetes should be aware of the possibility of inferior long-term outcomes after MIS spondylolisthesis surgery.

Patients who did not have a component of leg pain in their dominant clinical presentation fared worse with regard to disease-specific disability in our study. This finding is supported by prior investigations. In a study of 591 patients with degenerative spondylolisthesis (of whom $62 \%$ underwent surgery), a leg pain-predominant presentation was associated with superior outcomes at 2 years. ${ }^{33}$

\section{Socioeconomic Factors: Employment}

The relationship between employment and superior back pain and satisfaction following MIS spondylolisthesis surgery may be a function of patient selection. Patients who are employed preoperatively may reflect a subset of patients with greater social support, job satisfaction, job security and income, and adaptive psychological states., ${ }^{2,39,17}$ These factors may accelerate recovery and participation in physical therapy and thus improve back pain and satisfaction. Likewise, patients with more labor-intensive occupations may not be able to abide by appropriate postoperative restrictions and may exacerbate their pain following surgery. These protective factors may aid the surgeon and patient in expectation setting and should be considered in the preoperative evaluation.

\section{Baseline PROs}

The intimate relationship between baseline and followup PRO scores has been reported previously. ${ }^{24}$ Here, it is a 
reflection of our outcome metric reflecting a change score as opposed to absolute score. Namely, patients with worse ODI, back pain, leg pain, and EQ-5D at baseline will have the opportunity to achieve the greatest improvement from baseline, as those with less severe baseline disease will be susceptible to floor and ceiling effects.

\section{Study Limitations}

This study utilized information from a large, multicenter, prospective registry and thus has the associated limitations. Data presented herein were analyzed retrospectively from a prospectively designed registry and thus the findings are susceptible to bias. As a registry, there is no standardization of patient selection or operative technique. However, the results should be interpreted under the context that multivariate analytical methods-correcting for potential confounding variables-were utilized. The present prospective registry does not include postoperative radiographs. Therefore, we are unable to determine the presence of radiographic fusion, which may influence outcomes as well. Similarly, our study does not include baseline or postoperative radiographic parameters. Radiographic parameters may also affect 24-month outcomes and should be investigated in future studies on MIS for spondylolisthesis. Lastly, in comparing MIS TLIF and MIS decompression, cost-effectiveness is an important consideration and was beyond the scope of the present investigation. Future study should explore health-resource utilization data in comparing MIS TLIF and MIS decompression.

Despite these limitations, this study represents one of the largest, multiinstitutional studies-utilizing prospectively collected data-comparing patients receiving MIS TLIF and MIS decompression for grade 1 degenerative lumbar spondylolisthesis. Predictors reported herein reflect the "real world" practice patterns of high-volume spine centers in the United States and the results may be shared with patients to aid in patient selection and expectation setting.

\section{Conclusions}

For symptomatic, single-level degenerative spondylolisthesis, MIS TLIF was associated with fewer reoperations and superior outcomes for disability, back pain, and patient satisfaction compared to posterior MIS decompression alone. Additionally, preoperative active employment was a significant predictor of superior PROs. The presence of diabetes mellitus and a back pain-predominant presentation were associated with inferior outcomes. These findings may aid in surgical decision-making and expectation setting when considering MIS for degenerative lumbar spondylolisthesis.

\section{Acknowledgments}

We thank all of the site research coordinators for their help with data extraction and validation. We also thank the Neurosurgery Research and Education Foundation for its financial support of this work.

\section{References}

1. Adogwa O, Parker SL, Bydon A, Cheng J, McGirt MJ: Com- parative effectiveness of minimally invasive versus open transforaminal lumbar interbody fusion: 2-year assessment of narcotic use, return to work, disability, and quality of life. $\mathbf{J}$ Spinal Disord Tech 24:479-484, 2011

2. Anderson PA, Schwaegler PE, Cizek D, Leverson G: Work status as a predictor of surgical outcome of discogenic low back pain. Spine (Phila Pa 1976) 31:2510-2515, 2006

3. Asher AL, Devin CJ, Archer KR, Chotai S, Parker SL, Bydon M, et al: An analysis from the Quality Outcomes Database, Part 2. Predictive model for return to work after elective surgery for lumbar degenerative disease. J Neurosurg Spine 27:370-381, 2017

4. Asher AL, Kerezoudis P, Mummaneni PV, Bisson EF, Glassman SD, Foley KT, et al: Defining the minimum clinically important difference for grade I degenerative lumbar spondylolisthesis: insights from the Quality Outcomes Database. Neurosurg Focus 44(1):E2, 2018

5. Booth KC, Bridwell KH, Eisenberg BA, Baldus CR, Lenke LG: Minimum 5-year results of degenerative spondylolisthesis treated with decompression and instrumented posterior fusion. Spine (Phila Pa 1976) 24:1721-1727, 1999

6. Bridwell KH, Sedgewick TA, O’Brien MF, Lenke LG, Baldus $\mathrm{C}$ : The role of fusion and instrumentation in the treatment of degenerative spondylolisthesis with spinal stenosis. J Spinal Disord 6:461-472, 1993

7. Chan AK, Bisson EF, Bydon M, Glassman SD, Foley KT, Potts EA, et al: Laminectomy alone versus fusion for grade 1 lumbar spondylolisthesis in 426 patients from the prospective Quality Outcomes Database. J Neurosurg Spine 30:234241, 2019

8. Chan AK, Bisson EF, Bydon M, Glassman SD, Foley KT, Potts EA, et al: Women fare best following surgery for degenerative lumbar spondylolisthesis: a comparison of the most and least satisfied patients utilizing data from the Quality Outcomes Database. Neurosurg Focus 44(1):E3, 2018

9. Cole DC, Ibrahim S, Shannon HS, Scott FE, Eyles J: Work and life stressors and psychological distress in the Canadian working population: a structural equation modelling approach to analysis of the 1994 National Population Health Survey. Chronic Dis Can 23:91-99, 2002

10. Dhall SS, Wang MY, Mummaneni PV: Clinical and radiographic comparison of mini-open transforaminal lumbar interbody fusion with open transforaminal lumbar interbody fusion in 42 patients with long-term follow-up. J Neurosurg Spine 9:560-565, 2008

11. Dyck PJ, Karnes JL, O’Brien P, Okazaki H, Lais A, Engelstad J: The spatial distribution of fiber loss in diabetic polyneuropathy suggests ischemia. Ann Neurol 19:440-449, 1986

12. Dyrda L: Minimally invasive vs. open spine surgery: 6 key points. Becker's Spine Review. January 30, 2014. (https:// www.beckersspine.com/spine/item/19204-minimallyinvasive-vs-open-spine-surgery-6-key-points) [Accessed March 8, 2019]

13. Försth P, Ólafsson G, Carlsson T, Frost A, Borgström F, Fritzell P, et al: A randomized, controlled trial of fusion surgery for lumbar spinal stenosis. N Engl J Med 374:14131423,2016

14. Freedman MK, Hilibrand AS, Blood EA, Zhao W, Albert TJ, Vaccaro AR, et al: The impact of diabetes on the outcomes of surgical and nonsurgical treatment of patients in the spine patient outcomes research trial. Spine (Phila Pa 1976) 36:290-307, 2011

15. Ghogawala Z, Benzel EC, Amin-Hanjani S, Barker FG II, Harrington JF, Magge SN, et al: Prospective outcomes evaluation after decompression with or without instrumented fusion for lumbar stenosis and degenerative Grade I spondylolisthesis. J Neurosurg Spine 1:267-272, 2004 
16. Ghogawala Z, Dziura J, Butler WE, Dai F, Terrin N, Magge $\mathrm{SN}$, et al: Laminectomy plus fusion versus laminectomy alone for lumbar spondylolisthesis. N Engl J Med 374:14241434,2016

17. Gum JL, Glassman SD, Carreon LY: Is type of compensation a predictor of outcome after lumbar fusion? Spine (Phila Pa 1976) 38:443-448, 2013

18. Herkowitz HN: Spine update. Degenerative lumbar spondylolisthesis. Spine (Phila Pa 1976) 20:1084-1090, 1995

19. Kalichman L, Kim DH, Li L, Guermazi A, Berkin V, Hunter DJ: Spondylolysis and spondylolisthesis: prevalence and association with low back pain in the adult community-based population. Spine (Phila Pa 1976) 34:199-205, 2009

20. Konno S, Kikuchi S: Prospective study of surgical treatment of degenerative spondylolisthesis: comparison between decompression alone and decompression with graf system stabilization. Spine (Phila Pa 1976) 25:1533-1537, 2000

21. Kreines K, Johnson E, Albrink M, Knatterud GL, Levin ME, Lewitan A, et al: The course of peripheral vascular disease in non-insulin-dependent diabetes. Diabetes Care 8:235-243, 1985

22. Liang HF, Liu SH, Chen ZX, Fei QM: Decompression plus fusion versus decompression alone for degenerative lumbar spondylolisthesis: a systematic review and meta-analysis. Eur Spine J 26:3084-3095, 2017

23. Matsunaga S, Sakou T, Morizono Y, Masuda A, Demirtas AM: Natural history of degenerative spondylolisthesis. Pathogenesis and natural course of the slippage. Spine (Phila Pa 1976) 15:1204-1210, 1990

24. McGirt MJ, Bydon M, Archer KR, Devin CJ, Chotai S, Parker SL, et al: An analysis from the Quality Outcomes Database, Part 1. Disability, quality of life, and pain outcomes following lumbar spine surgery: predicting likely individual patient outcomes for shared decision-making. J Neurosurg Spine 27:357-369, 2017

25. McGirt MJ, Parker SL, Lerner J, Engelhart L, Knight T, Wang MY: Comparative analysis of perioperative surgical site infection after minimally invasive versus open posterior/ transforaminal lumbar interbody fusion: analysis of hospital billing and discharge data from 5170 patients. J Neurosurg Spine 14:771-778, 2011

26. McGirt MJ, Speroff T, Dittus RS, Harrell FE Jr, Asher AL: The National Neurosurgery Quality and Outcomes Database (N2QOD): general overview and pilot-year project description. Neurosurg Focus 34(1):E6, 2013

27. Meyerding HW: Diagnosis and roentgenologic evidence of spondylolisthesis. Radiology 20:108-120, 1933

28. Mummaneni PV, Bisson EF, Kerezoudis P, Glassman S, Foley $\mathrm{K}$, Slotkin JR, et al: Minimally invasive versus open fusion for Grade I degenerative lumbar spondylolisthesis: analysis of the Quality Outcomes Database. Neurosurg Focus 43(2):E11, 2017

29. Nork SE, Hu SS, Workman KL, Glazer PA, Bradford DS: Patient outcomes after decompression and instrumented posterior spinal fusion for degenerative spondylolisthesis. Spine (Phila Pa 1976) 24:561-569, 1999

30. Park JH, Hyun SJ, Roh SW, Rhim SC: A comparison of unilateral laminectomy with bilateral decompression and fusion surgery in the treatment of grade I lumbar degenerative spondylolisthesis. Acta Neurochir (Wien) 154:1205-1212, 2012

31. Parker SL, Adogwa O, Witham TF, Aaronson OS, Cheng J, McGirt MJ: Post-operative infection after minimally invasive versus open transforaminal lumbar interbody fusion (TLIF): literature review and cost analysis. Minim Invasive Neurosurg 54:33-37, 2011

32. Parker SL, Mendenhall SK, Shau DN, Zuckerman SL, Godil SS, Cheng JS, et al: Minimally invasive versus open transforaminal lumbar interbody fusion for degenerative spondylolisthesis: comparative effectiveness and cost-utility analysis. World Neurosurg 82:230-238, 2014

33. Pearson A, Blood E, Lurie J, Abdu W, Sengupta D, Frymoyer JW, et al: Predominant leg pain is associated with better surgical outcomes in degenerative spondylolisthesis and spinal stenosis: results from the Spine Patient Outcomes Research Trial (SPORT). Spine (Phila Pa 1976) 36:219-229, 2011

34. Peng CW, Yue WM, Poh SY, Yeo W, Tan SB: Clinical and radiological outcomes of minimally invasive versus open transforaminal lumbar interbody fusion. Spine (Phila Pa 1976) 34:1385-1389, 2009

35. Schizas C, Tzinieris N, Tsiridis E, Kosmopoulos V: Minimally invasive versus open transforaminal lumbar interbody fusion: evaluating initial experience. Int Orthop 33:1683-1688, 2009

36. Shunwu F, Xing Z, Fengdong Z, Xiangqian F: Minimally invasive transforaminal lumbar interbody fusion for the treatment of degenerative lumbar diseases. Spine (Phila Pa 1976) 35:1615-1620, 2010

37. Tsutsumimoto T, Shimogata M, Ohta H, Misawa H: Mini-open versus conventional open posterior lumbar interbody fusion for the treatment of lumbar degenerative spondylolisthesis: comparison of paraspinal muscle damage and slip reduction. Spine (Phila Pa 1976) 34:1923-1928, 2009

38. Wang MY, Cummock MD, Yu Y, Trivedi RA: An analysis of the differences in the acute hospitalization charges following minimally invasive versus open posterior lumbar interbody fusion. J Neurosurg Spine 12:694-699, 2010

39. Weinstein JN, Lurie JD, Tosteson TD, Hanscom B, Tosteson AN, Blood EA, et al: Surgical versus nonsurgical treatment for lumbar degenerative spondylolisthesis. N Engl J Med 356:2257-2270, 2007

\section{Disclosures}

Dr. Chan: support of non-study-related clinical or research effort from Orthofix. Dr. Bisson: consultant for nView. Dr. Glassman: employee of Norton Healthcare, consultant for Medtronic and K2M, and royalties from Medtronic and Springer. Dr. Foley: consultant for Medtronic; direct stock ownership in Medtronic, NuVasive, Spine Wave, and Discgenics; patent holder with and royalties for licensed patents from Medtronic. Dr. Coric: consultant for Medtronic, Spine Wave, Stryker, Globus Medical, and Integrity Implants. Dr. Park: consultant for Globus, NuVasive, Allosource, and Medtronic; and royalties from Globus. Dr. Wang: consultant for DePuy Spine, K2M, Spineology, and Stryker; patent holder with DePuy Synthes Spine; and direct stock ownership in ISD. Dr. Fu: SI-BONE, J and J, and Globus. Dr. Slotkin: consultant for Stryker Spine and Medtronic. Dr. Haid: consultant for NuVasive; direct stock ownership in NuVasive, Spine Wave, and Vertical Health; royalties from NuVasive, Medtronic Sofamor Danek, and Elsevier; and patent holder with Medtronic Sofamor Danek. Dr. Mummaneni: consultant for DePuy Spine, Globus, and Stryker; direct stock ownership in Spinicity/ISD; clinical research support for this study from NREF; royalties from DePuy Spine, Thieme Publishing, and Springer Publishing; and honoraria from AOSpine and Spineart.

\section{Author Contributions}

Conception and design: Chan, Bisson, Bydon, Knightly, Park, Wang, Fu, Slotkin, Mummaneni. Acquisition of data: Chan, Kerezoudis, Alvi, Guan. Analysis and interpretation of data: Chan, Kerezoudis, Alvi, Mummaneni. Drafting the article: all authors. Critically revising the article: all authors. Reviewed sub- 
Chan et al.

mitted version of manuscript: all authors. Approved the final version of the manuscript on behalf of all authors: Chan. Statistical analysis: Chan. Administrative/technical/material support: Bisson, Bydon, Haid, Mummaneni. Study supervision: Bisson, Bydon,

Haid, Mummaneni.

\section{Supplemental Information}

Videos

Video Abstract. https://vimeo.com/329092460.

\section{Correspondence}

Andrew K. Chan: University of California, San Francisco, CA. andrew.chan@ucsf.edu. 